Sir,

\section{OCT vitreoretinal interface patterns}

Eye (2003) 17, 541-542. doi:10.1038/sj.eye.6700438

There are increasing uncontrolled data to suggest that pars plana vitrectomy (PPV) may be beneficial in patients with diffuse diabetic macular oedema (DDMO). This treatment is not however universally efficacious and many questions remain regarding the subsets of patients (if any) who are most likely to benefit from surgery. Most of the data suggesting benefit relate to patients with a taut thickened posterior hyaloid (TTPH) ${ }^{1-4}$ This is a clinical sign where the premacular posterior hyaloid has an exaggerated glistening appearance in the absence of signs associated with retinal traction, such as striae, retinal detachment, or altered vascular tortuosity. ${ }^{3}$ Using optical coherence tomography (OCT), such patients have been found to have partial posterior hyaloid separation and a 'traction macular detachment'. ${ }^{5}$ We and others have found that a similar OCT appearance occurs in the absence of a clinically evident $\mathrm{TTPH}^{6-8}$ and hypothesise that patients with partial vitreoretinal separation on OCT, but no clinical evidence of a TTPH, may also benefit from PPV. We present such a case and discuss the visual and anatomical results.

\section{Case report}

A 67-year-old patient with diabetes presented with a 20-year history of macular oedema and subsequent proliferative retinopathy (PDR) affecting each eye. The right eye had failed to respond to four macular grids as well as panretinal photocoagulation (PRP), and his visual acuity had deteriorated from $6 / 6$ to counting fingers vision because of persistent DDMO. Similarly, the left eye had failed to respond to five macular grids as well as PRP, resulting in a deterioration of his left visual acuity from $6 / 6$ to $6 / 18$. No traction was found on clinical examination using a 66 dioptre lens, and the vitreoretinal interface showed no clinical evidence of a TTPH.

Fluorescein angiography revealed diffuse diabetic macular oedema with a deep diffuse late leakage pattern in both eyes and no significant macular ischaemia in either eye. OCT revealed a pattern reminiscent of the dome-shaped elevation described by Patel et al, ${ }^{7}$ with partial posterior hyaloid separation in both eyes.

Vitrectomy with internal limiting membrane (ILM) peel was performed asynchronously on both eyes. Pre- and postoperative acuity and OCT central macular thickness data (using Humphrey-Zeiss ${ }^{\circledR}$ OCT mapping software version 6.2) are presented in Table 1.

\section{Comment}

Identifying patients who will benefit from surgery on the basis of OCT patterns is a current area of research in diabetic macular oedema. Preliminary reports suggest that OCT may provide valuable information in this regard. ${ }^{9,10}$

The OCT patterns in diabetic macular oedema are currently classified into domed and diffuse, that is, with or without an area of perifoveal elevation. There is speculation that patients with a domed pattern and focal vitreoretinal separation on OCT may respond to surgery, but these data are as yet unpublished. ${ }^{7,8}$

Table 1 Pre- and postoperative OCT and visual acuity results

\begin{tabular}{|c|c|c|c|c|}
\hline & \multicolumn{2}{|c|}{ Right eye } & \multicolumn{2}{|c|}{ Left eye } \\
\hline & Preoperative & Postoperative & Preoperative & Postoperative \\
\hline \multicolumn{5}{|l|}{ OCT } \\
\hline $\begin{array}{l}\text { Central } \\
\text { foveal } \\
\text { thickness }\end{array}$ & $589( \pm 216) \mu \mathrm{m}$ & $179( \pm 26) \mu \mathrm{m}$ & $633( \pm 5) \mu \mathrm{m}$ & $201( \pm 4) \mu \mathrm{m}$ \\
\hline \multirow{2}{*}{$\begin{array}{l}\text { LogMAR } \\
\text { visual } \\
\text { acuity } \\
\text { (Snellen) }\end{array}$} & CF & D: 1.38 (CF) & D: $0.50(6 / 18)$ & D: $0.32(6 / 12)$ \\
\hline & & N: 1.40 (N50) & $\mathrm{N}: 0.60(\mathrm{~N} 8)$ & $\mathrm{N}: 0.60(\mathrm{~N} 8)$ \\
\hline
\end{tabular}


Kaiser $e t a l^{5}$ have described images of the vitreoretinal interface in the context of a clinically evident TTPH showing a partial posterior vitreous separation on OCT, apparently indicating vitreoretinal traction. They hypothesise that vitrectomy may be beneficial in this group of patients because it relieves traction and allows resolution of a shallow traction retinal detachment. Duguid $e t a l^{8}$ and Patel $e t a l^{7}$ have reported patients with a similar pattern on OCT without a clinically evident TTPH. The patient that we present has responded well to vitrectomy. Preoperatively there was no clinically detectable TTPH, and OCT revealed a dome-shaped elevation with partial vitreoretinal separation (white arrows), suggesting that this OCT pattern may be useful in identifying patients who will potentially benefit from surgery regardless of the clinical appearance of the premacular posterior hyaloid.

Vitrectomy for macular oedema is not universally efficacious, and further investigation is clearly required into the efficacy of surgery in patients with DDMO. We are currently conducting a randomised controlled trial to evaluate the benefit of surgery in such patients. This case shows that patients with no clinical evidence of a TTPH may achieve and sustain anatomical and visual improvement following surgery. Further investigation into the OCT vitreoretinal interface pattern as a potential predictor of surgical outcome is warranted.

\section{Acknowledgement}

Proprietary interests: None.

\section{References}

1 Gandorfer A, Messmer EM, Ulbig MW, Kampik A. Resolution of diabetic macular edema after surgical removal of the posterior hyaloid and the inner limiting membrane. Retina 2000; 20: 126-133.

2 Harbour JW, Smiddy WE, Flynn Jr HW, Rubsamen PE. Vitrectomy for diabetic macular edema associated with a thickened and taut posterior hyaloid membrane. Am J Ophthalmol 1996; 121: 405-413.

3 Lewis H, Abrams GW, Blumenkranz MS, Campo RV. Vitrectomy for diabetic macular traction and edema associated with posterior hyaloidal traction. Ophthalmology 1992; 99: 753-759.

4 Pendergast SD, Hassan TS, Williams GA, Cox MS, Margherio RR, Ferrone PJ et al. Vitrectomy for diffuse diabetic macular edema associated with a taut premacular posterior hyaloid. Am J Ophthalmol 2000; 130: 178-186.

5 Kaiser PK, Riemann CD, Sears JE, Lewis H. Macular traction detachment and diabetic macular edema associated with posterior hyaloidal traction. Am J Ophthalmol 2001; 131: $44-49$.

6 Thomas D, Moorman C, Laidlaw DAH. How prevalent is a taut thickened posterior hyaloid? [abstract] 2002 Annual Meeting Abstract and Programme Planner [on CD-ROM].
Association for Research in Vision and Ophthalmology. Abstract 3467.

7 Patel JI, Cree IA, Gregor ZJ, Boulton ME, Hykin PG. Vascular endothelial growth factor and diabetic macular oedema [ARVO Abstract]. Invest Ophthalmol Vis Sci 2001; 42: Abstract no. 3974.

8 Duguid G, Massin P, Houchine B, Erginay A, Gaudric A. Vitrectomy for diabetic macular edema: the effect on visual acuity and optical coherence tomography [ARVO abstract]. Invest Ophthalmol Vis Sci 2000; 41: Abstract no. 585.

9 Otani T, Kishi S, Maruyama Y. Patterns of diabetic macular edema with optical coherence tomography. Am J Ophthalmol 1999; 127: 688-693.

10 Giovannini A, Amato G, Mariotti C, Scassellati-Sforzolini B. Optical coherence tomography findings in diabetic macular edema before and after vitrectomy. Ophthalmic Surg Lasers 2000; 31: 187-191.

\section{Thomas and DAH Laidlaw}

The Vitreoretinal Unit

Department of Ophthalmology

St Thomas' Hospital Lambeth Palace Road

London SE1 7EH, UK

Correspondence: D Thomas

Tel: +44 $2079289292 \times 3239$

Fax: +44 2079228165

E-mail: Dhanes.Thomas@gstt.sthames.nhs.uk

Sir,

Acute posterior multifocal placoid pigment epitheliopathy associated with adenovirus infection Eye (2003) 17, 542-544. doi:10.1038/sj.eye.6700389

The aetiology of acute posterior multifocal placoid pigment epitheliopathy (APMPPE) remains a subject of debate. Our patient represents the second reported case of APMPPE associated with adenoviral infection. ${ }^{1}$

\section{Case report}

A 37-year-old Caucasian male presented with acute bilateral blurring of vision. He also reported a 3-week period of prodromal general malaise with symptoms of myalgia, arthralgia, headache and nonproductive cough. He had no significant past history and was not taking any regular medication. Family history was negative.

Visual acuities at presentation were right eye (RE) 6/24 and left eye (LE) 6/36. Anterior and vitreous chambers were quiet. Fundoscopy showed subtle perifoveal pallor. The next day visual acuities had fallen to 6/60 in both eyes. Ocular examination revealed slightly injected bulbar conjunctivae and $<1+$ anterior chamber cells 